\title{
RESEARCH
}

\section{Suitability of recommended limits for fasting glucose tests in women with polycystic ovary syndrome}

\author{
Claudia Gagnon, Jean-Patrice Baillargeon
}

$\infty \quad$ See related article page $95 \mathrm{I}$

\section{ABSTRACT}

Background: The Canadian and American Diabetes Associations recommend the use of an oral glucose tolerance test to screen for abnormal glucose tolerance among women with polycystic ovary syndrome when their fasting plasma glucose level is $5.7 \mathrm{mmol} / \mathrm{L}$ or more (Canadian guideline) and $5.6 \mathrm{mmol} / \mathrm{L}$ or more (American). Our objective was to determine the predictive value of $5.6 \mathrm{mmol} / \mathrm{L}$ as a fasting plasma glucose cutoff for detecting abnormal glucose tolerance in women with polycystic ovary syndrome, and then to define the optimal cutoff for this population.

Methods: An oral glucose tolerance test was administered to 105 consecutive women with polycystic ovary syndrome referred to an academic reproductive endocrine clinic. We calculated sensitivity, specificity and likelihood ratios.

Results: The sensitivity of a $5.6 \mathrm{mmol} / \mathrm{L}$ cutoff was $48 \%(95 \%$ confidence interval $[\mathrm{Cl}] 30 \%-67 \%$ ); its specificity, $98.7 \%$ ( $95 \% \mathrm{Cl} 96.1 \%-100 \%$ ). With this cutoff, $52 \%$ of women with polycystic ovary syndrome whose glucose tolerance is abnormal would be missed. The prevalence of abnormal glucose tolerance was $28 \%$, with a positive predictive value of $93 \%$ (95\% $\mathrm{Cl} 81 \%-100 \%)$ and a negative predictive value of $83 \%(95 \% \mathrm{Cl}$ $76 \%-91 \%)$. The likelihood ratio for a positive test was 36.7 $(95 \% \mathrm{Cl} 5.0-267)$, and for a negative test, 0.5 (95\% Cl $0.4-$ $0.7)$. The optimal fasting plasma glucose cutoff value was $5.0 \mathrm{mmol} / \mathrm{L}$, with a $79 \%$ sensitivity ( $95 \% \mathrm{Cl} 65 \%-94 \%)$ and $66 \%$ specificity ( $95 \% \mathrm{Cl} 55 \%-77 \%$ ). If this cutoff were used, $24 \%$ of women with abnormal glucose tolerance would still be missed.

Interpretation: The Canadian and American recommendations - of screening for abnormal glucose tolerance with an oral glucose tolerance test only when the results of a fasting plasma glucose test are $5.7 \mathrm{mmol} / \mathrm{L}$ (or $5.6 \mathrm{mmol} / \mathrm{L}$ ) or more - are inappropriate for women with polycystic ovary syndrome. We therefore recommend that all women with polycystic ovary syndrome have an oral glucose tolerance test.

CMAJ 2007;176(7):933-8

$\mathrm{P}$ olycystic ovary syndrome is a common disorder affecting some $6 \%-10 \%$ of women of reproductive age. ${ }^{1-3} \mathrm{Al}-$ though it is the clinical manifestations of chronic anovulation and hyperandrogenemia that usually bring these women to visit a physician, insulin resistance and hyperinsu- linemia are also frequent in this population ${ }^{4-10}$ and play an important etiologic role. ${ }^{11-17}$ Indeed, the prevalence rates of impaired glucose tolerance and type 2 diabetes in women with this syndrome are both higher than expected for women of similar age, reaching 30\%-40\% and 10\%, respectively. ${ }^{18,19}$ Moreover, hypertension, an atherogenic lipid profile and obesity are more prevalent in this population than among agematched control subjects. ${ }^{20,21}$ This adverse metabolic profile contributes to an excess cardiovascular risk in this youthful population..$^{22,23}$

Since abnormal glucose tolerance is a major cardiovascular risk factor, it is important that it be detected early. The progression to type 2 diabetes can be prevented by lifestyle changes in people whose glucose tolerance is impaired. ${ }^{24,25}$

Despite some evidence that fasting plasma glucose testing does not reliably predict abnormal glucose tolerance in women with polycystic ovary syndrome ${ }^{18,26}$ current Canadian and American guidelines still rely mainly upon this test for screening. Notably, guidelines from the Canadian Diabetes Association ${ }^{27}$ recommend an oral glucose tolerance test for people at risk (including women with polycystic ovary syndrome) only when their fasting plasma glucose result reaches $5.7 \mathrm{mmol} / \mathrm{L}$ or more. The American Diabetes Association suggests that screening for abnormal glucose tolerance be considered for young patients if they are overweight and present another risk factor for diabetes, such as polycystic ovary syndrome (level of evidence E). ${ }^{28}$ Furthermore, the US association does not recommend an oral glucose tolerance test over a fasting plasma test for screening (level B) unless the results of a fasting plasma glucose test are $5.6 \mathrm{mmol} / \mathrm{L}$ or more (level E). Because the fasting tests are, in most clinical settings, easier to perform as well as less expensive, most clinicians applying these recommendations will therefore not conduct oral glucose tolerance tests when their patient's fasting plasma glucose measurement meets or exceeds 5.7 (or 5.6) $\mathrm{mmol} / \mathrm{L}$.

Since fasting plasma glucose results have been shown to be not well correlated with abnormal glucose tolerance in women with polycystic ovary syndrome, we hypothesized that these recommendations may be inappropriate for patients with that syndrome. The aim of this study was therefore to determine the predictive value of a fasting plasma glucose cutoff of $5.6 \mathrm{mmol} / \mathrm{L}$ to identify people with abnormal glucose tolerance among those with polycystic ovary syndrome, and to define the optimal cutoff for the fasting test for this 
subpopulation. We performed our analyses with the American Diabetes Association's more conservative fasting plasma glucose cutoff because, if our hypothesis was true, our conclusion would also apply to the Canadian Diabetes Association's slightly higher recommendation $(\geq 5.7 \mathrm{mmol} / \mathrm{L})$.

\section{Methods}

This retrospective study looked at test results for I 68 consecutive women with polycystic ovary syndrome referred to the Reproductive Endocrine Clinic of the Centre hospitalier universitaire de Sherbrooke from August 2003 through December 2005. All women met the established criteria for the diagnosis of polycystic ovary syndrome: ${ }^{29,30}$ oligomenorrhea $(\leq 8$ menstrual periods during the preceding year) or anovulation, as well as clinical or biochemical signs of hyperandrogenism (serum total testosterone results $>2.6 \mathrm{nmol} / \mathrm{L}$ and calculated free testosterone $>50 \mathrm{pmol} / \mathrm{L}$ ). Of these patients, I05 had been screened with a 2-hour 75-g oral glucose tolerance test and met none of our exclusion criteria: nonclassical congenital adrenal hyperplasia, abnormal thyroid function, hyperprolactinemia, evidence of androgen-secreting tumours or Cushing's syndrome, and having taken medications known to affect the metabolism of sex hormones or glucose tolerance during the month before testing ( $3 \mathrm{mo}$, for oral contraceptives).

Initial high levels of serum $\mathrm{I} 7 \alpha$-hydroxyprogesterone (i.e., $17-\mathrm{OHPg} \geq 10 \mathrm{nmol} / \mathrm{L}$ ) in 2 patients dropped to within a normal range after treatment with metformin. These subjects were included in the study because, in cases of nonclassical congenital adrenal hyperplasia, that effect is not expected.

Impaired glucose tolerance was classified according to 2006 American Diabetes Association and 2003 Canadian Diabetes Association diagnostic criteria:: ${ }^{27,28} 2$ hours after the glucose drink, a glucose measurement of 7.8-II.I mmol/L constituted impaired glucose tolerance; a level of II.I mmol/L or more defined a provisional diagnosis of diabetes mellitus (essentially, type 2). The study protocol was approved by the Institutional Review Board of the Centre hospitalier universitaire de Sherbrooke.

Blood samples were assayed at the hospital's clinical laboratory. Total testosterone, dehydroepiandrosterone sulfate (DHEAS) and 17-OHPg levels were determined by radioimmunoassay; sex-hormone binding globulin, by immunoradiometric assay. Serum concentrations of free testosterone were calculated by means of the method of Sodergard and colleagues, ${ }^{31}$ with a standard serum albumin concentration of $40 \mathrm{~g} / \mathrm{L}$. Progesterone, follicle-stimulating hormone, luteinizing hormone, thyroid-stimulating hormone, prolactin, glucose, total cholesterol, triglycerides and high-density lipoprotein-

Table 1: Clinical and laboratory characteristics of the women involved in the study, by glucose tolerance

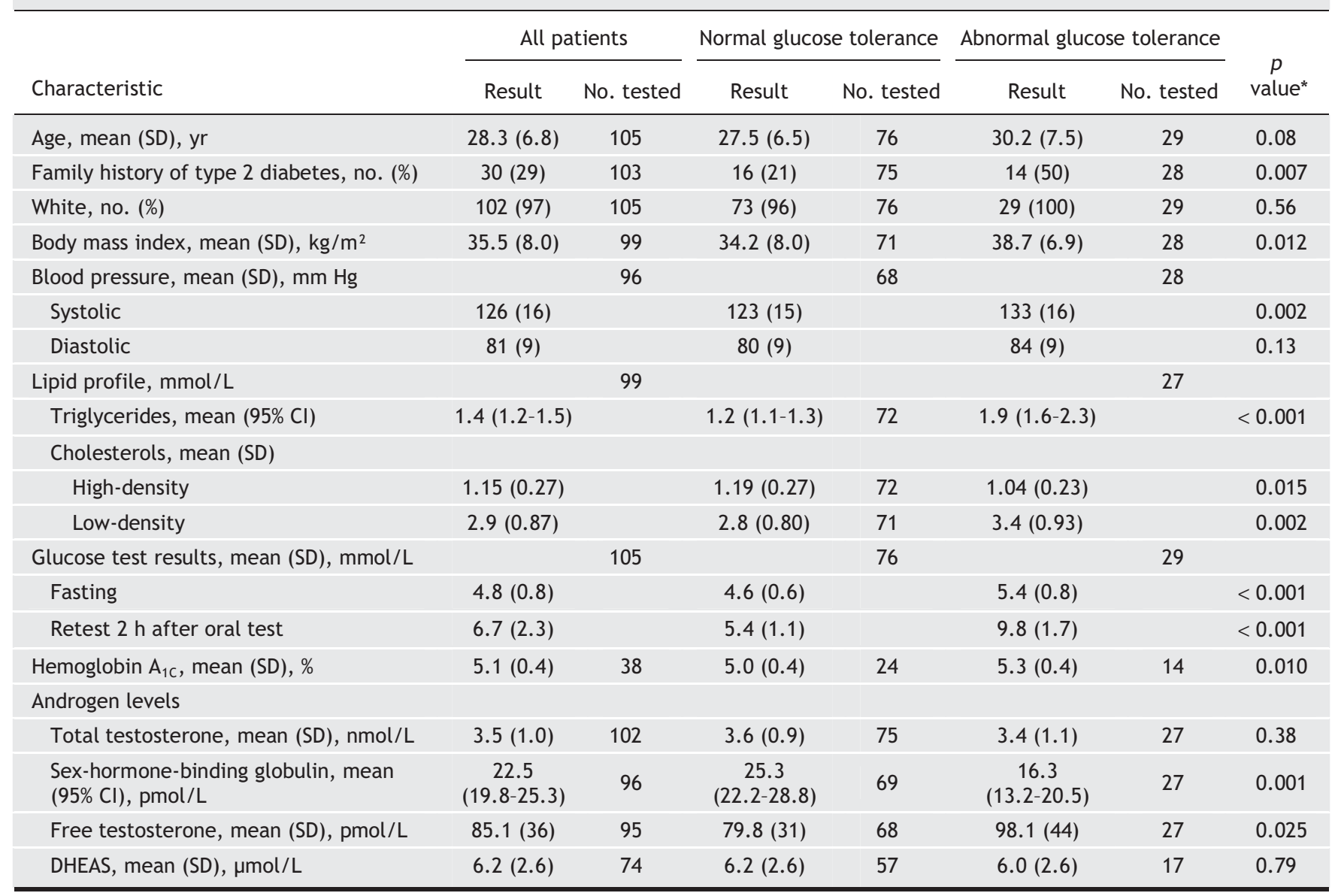

Note: $\mathrm{SD}=$ standard deviation, $\mathrm{Cl}$ = confidence interval, DHEAS = dehydroepiandrosterone sulfate.

$*$ Of the difference between the 2 glucose tolerance groups. 
cholesterol (HDL-C) were measured by chemiluminescence; low-density lipoprotein-cholesterol (LDL-C) concentrations were calculated with the Friedewald equation. ${ }^{32}$ Inter- and intraassay coefficients of variation were less than $10 \%$ for total testosterone and less than $8.5 \%$ for all other steroid hormones.

Differences between groups were assessed via Fisher's exact test for proportions, or the unpaired Student's $t$ test for continuous variables. Variables that were not normally distributed, as determined with the normal quantile plot test, were log-transformed for all statistical analyses, then backtransformed into their original units (geometric means with $95 \%$ confidence intervals) for this report.

To determine independent predictive factors of abnormal glucose tolerance, we used a forward stepwise multivariable analysis by successively entering in the model variables that were found in univariate analyses to be significantly associated with abnormal glucose tolerance $(p \leq 0.10)$, based on the nextlowest $p$ value. At each step, variables that did not contribute significantly to the model (i.e., partial $p>0.05$ ) were excluded.

The sensitivity, specificity, positive and negative predictive values, and likelihood ratios for positive and for negative test results were determined with use of a fasting plasma glucose cutoff of $5.6 \mathrm{mmol} / \mathrm{L}$. A receiver operating characteristic (ROC) curve was generated to define the optimal cutoff for fasting plasma glucose testing, which corresponds to the point closest to the upper left corner of the graph. For all analyses, a 2-tailed $p$ value of 0.05 or less was considered statistically significant. Unless specified otherwise, data are presented as means and standard deviations.

\section{Results}

Subjects' clinical and laboratory characteristics are summarized in Table I. Glucose tolerance results were abnormal in

Table 2: Test characteristics with the fasting plasma glucose cutoff ( $\geq 5.6 \mathrm{mmol} / \mathrm{L}$ ) recommended* for the use of an oral glucose tolerance test to screen for abnormal glucose tolerance

\begin{tabular}{|lrc|}
\hline Characteristic & \multicolumn{2}{c}{ Result, \%† (95\% Cl) } \\
\hline Positive test results & 14.3 & $(7.6-21.0)$ \\
\hline $\begin{array}{l}\text { Women with polycystic ovary syndrome } \\
\text { whose glucose tolerance was abnormal }\end{array}$ & 27.6 & $(19.0-36.2)$ \\
\hline \multicolumn{1}{|c|}{ Missed diagnoses within this group } & 51.7 & $(33.5-69.9)$ \\
\hline Sensitivity & 48.3 & $(30.1-66.5)$ \\
\hline Specificity & 98.7 & $(96.1-100)$ \\
\hline Positive predictive value & 93.3 & $(80.7-100)$ \\
\hline Negative predictive value & 83.3 & $(75.6-91.0)$ \\
\hline $\begin{array}{l}\text { False-negative rate among all women } \\
\text { with polycystic ovary syndrome }\end{array}$ & 16.7 & $(9.0-24.4)$ \\
\hline Likelihood ratio for a test result that is & & \\
\hline \multicolumn{1}{|c|}{ Positive } & 36.7 & $(5.0-267)$ \\
\hline Negative & 0.5 & $(0.4-0.7)$ \\
\hline
\end{tabular}

Note: $\mathrm{Cl}=$ confidence interval.

*By the Canadian Diabetes Association. This limit includes that recommended by the American Diabetes Association ( $\geq 5.7 \mathrm{mmol} / \mathrm{L}$ ).

†Except for likelihood ratios. 2-h glucose test result $\geq 7.8 \mathrm{mmol} / \mathrm{L}$

\begin{tabular}{|c|c|c|c|c|c|}
\hline \multirow{3}{*}{ 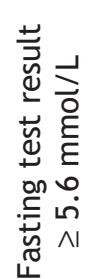 } & & Yes & No & Totals & \multirow{3}{*}{$\begin{aligned} \text { PPV: } & 14 / 15 \\
= & 93.3 \% \\
\text { NPV: } & 75 / 90 \\
= & 83.3 \%\end{aligned}$} \\
\hline & Yes & 14 & 1 & 15 & \\
\hline & No & 15 & 75 & 90 & \\
\hline & Totals: & 29 & 76 & $n=105$ & \\
\hline \multicolumn{6}{|c|}{$\begin{array}{cc}\text { Sensitivity } & \text { Specificity } \\
=14 / 29 & =75 / 76 \\
=48.3 \% & =98.7 \%\end{array}$} \\
\hline
\end{tabular}

Fig. 1: A $2 \times 2$ table showing the performance characteristics of the 2 -h glucose tolerance test (cutoff $\geq 7.8 \mathrm{mmol} / \mathrm{L}$ ) compared with the fasting plasma glucose test (cutoff $\geq 5.6 \mathrm{mmol} / \mathrm{L}$ ). PPV $=$ positive predictive value, NPV $=$ negative predictive value.

29 of the 105 women included in the study: 24 (23\%) had impaired glucose tolerance and $5(5 \%)$ had diabetes. All but 3 women were of Caucasian ethnicity. Mean age at presentation was 28 years (range $\mathrm{I} 4-47 \mathrm{yr}$ ) and the mean body mass index (BMI) was $35.5 \mathrm{~kg} / \mathrm{m}^{2}$ (range $19.0-54.8 \mathrm{~kg} / \mathrm{m}^{2}$ ).

Women with polycystic ovary syndrome whose glucose tolerance was abnormal or normal differed significantly in many characteristics. The prevalence of first-degree relatives with type 2 diabetes was more than doubled in subjects with abnormal glucose tolerance $(p=0.007)$. They were also significantly more obese ( $p=0.012)$ and had higher systolic blood pressures $(p=$ 0.002 ) than women with normal glucose tolerance. Moreover, they exhibited higher levels of triglycerides $(p<0.00 I)$ and LDL$\mathrm{C}(p=0.002)$, in addition to lower HDL-C levels $(p=0.015)$.

As expected, fasting glucose levels were higher in subjects with abnormal glucose tolerance $(5.4 \mathrm{mmol} / \mathrm{L} \mathrm{v} .4 .5 \mathrm{mmol} / \mathrm{L} ; p$ $<0.00 I$ ). Of note, the mean result of fasting plasma glucose testing remained below the cutoff limit of $5.6 \mathrm{mmol} / \mathrm{L}$ in the group with abnormal glucose tolerance, even though their mean 2hour glucose levels were much above $7.8 \mathrm{mmol} / \mathrm{L}$. Furthermore, concentrations of hemoglobin $\mathrm{A}_{1 \mathrm{C}}$ were significantly higher among women with abnormal glucose tolerance $(p=0.010)$. With regard to androgenic profiles, lower sex-hormone-binding globulin levels $(p=0.00 I)$ and higher free testosterone levels $(p=0.025)$ were predictive of abnormal glucose tolerance.

Finally, multivariable regression analyses found that fasting glucose $(p<0.00 I)$, triglycerides $(p=0.006)$ and LDL-C levels $(p=0.048)$ were independent predictive factors of abnormal glucose tolerance in women with polycystic ovary syndrome. ${ }^{22}$

Predictive values and likelihood ratios for the $5.6 \mathrm{mmol} / \mathrm{L}$ cutoff for fasting plasma glucose are shown in Table 2. (The procedure for calculating predictive values for the comparison is illustrated with a $2 \times 2$ table: Fig. I.) Notably, the $95 \%$ confidence interval (CI) of sensitivity was far below $80 \%$, the minimum generally recommended for a screening test. ${ }^{33,34}$ Indeed, with the use of this criterion, $52 \%$ of women with polycystic ovary syndrome whose glucose tolerance was abnormal would have been missed. The prevalence of abnormal 
glucose tolerance was $28 \%$ in the study group. From a screening perspective, the likelihood ratio for a negative test result (0.5, in this comparison) is the more important ratio; ideally, it should be less than o.I to rule out the condition tested for. ${ }^{33}$ According to our findings, a woman with polycystic ovary syndrome and a fasting plasma glucose concentration below $5.6 \mathrm{mmol} / \mathrm{L}$ still has a $17 \%$ chance of having diabetes.

To determine the optimal cutoff for screening, we calculated an ROC curve (Fig. 2). The fasting plasma glucose cutoff with optimal specificity and sensitivity (determined via the "knee" of the curve) ${ }^{35}$ in women with polycystic ovary syndrome for performing an oral glucose tolerance test was established as $\geq 5.0 \mathrm{mmol} / \mathrm{L}$ (sensitivity 76\%, 95\% CI 60\%91\%; specificity $78 \%$, 95\% CI 68\%-87\%).

Since the glucose tolerance of $28 \%$ of the study group was abnormal, the positive predictive value was $56 \%(95 \%$ CI $4 \mathrm{I} \%-$ $72 \%$ ) and the negative predictive value, $89 \%$ (95\% CI $82 \%-$ $97 \%$ ). The likelihood ratios for a positive and a negative test were, respectively, 3.4 (95\% CI 2.I-5.4) and 0.3 (95\% CI 0.2o.6). This likelihood ratio for a negative test is still high for a screening test, i.e., above o.I. Thus, if this strict fasting plasma glucose cutoff were applied, $37 \%$ of all women with polycystic ovary syndrome would have a positive result and be required to undergo an oral glucose tolerance test. Among our study subjects, $56 \%$ of those with a positive test result actually had diabetes, and $\mathrm{II} \%$ of those with a negative result.

Logarithmic modelling of likelihood ratios as a function of fasting plasma glucose values is shown in Fig. 3 (as recommended by Albert $^{36}$ and by Sackett and his collaborators ${ }^{33}$ ). This figure is useful to determine the likelihood of having abnormal as opposed to normal glucose tolerance, for a specific fasting plasma glucose value. In consideration of the normal distribu-

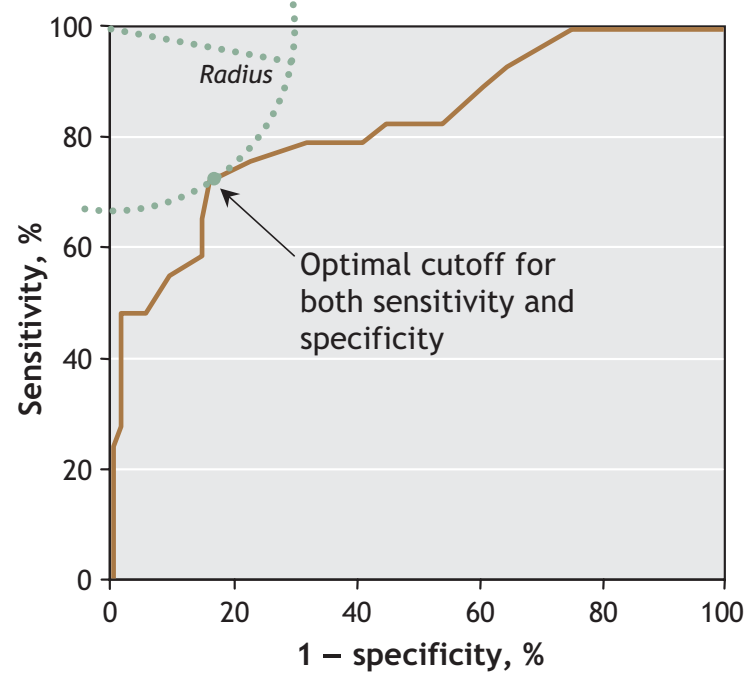

Fig. 2: Receiver operating characteristic curve of the association between fasting plasma glucose and abnormal glucose tolerance. The area under the curve was 0.828 (95\% confidence interval $0.735^{-0.921)}$. The optimal cutoff for the test is the point closest to the upper-left corner of the graph, which corresponds to a fasting plasma glucose measurement of $5.0 \mathrm{mmol} / \mathrm{L}$. tion of data in both the abnormal and normal glucose tolerance groups, and after adjustment was made for the unequal number of subjects in the 2 groups, a likelihood ratio of I.O (the dotted line in Fig. 3) meant that the likelihood of a fasting plasma glucose of $4.4 \mathrm{mmol} / \mathrm{L}$ in patients with abnormal glucose tolerance is equal to the likelihood of finding this level among those without abnormal tolerance. Thus, likelihood ratios below I.o indicate that likelihoods of having normal glucose tolerance readings are increasingly high. Accordingly, fasting plasma glucose values, to rule out abnormal glucose tolerance, must be very low.

Specifically, a likelihood ratio of o.I is found with a fasting plasma glucose result of $3.0 \mathrm{mmol} / \mathrm{L}$; 0.5 , with a result of $4.0 \mathrm{mmol} / \mathrm{L}$; I.O, with a result of $4.4 \mathrm{mmol} / \mathrm{L} ; 2$, with a result of $4.8 \mathrm{mmol} / \mathrm{L}$; and Io, with a test result of $5.8 \mathrm{mmol} / \mathrm{L}$.

\section{Interpretation}

Our study adds to the cumulating data showing that metabolic abnormalities occur at a young age in women with polycystic ovary syndrome. ${ }^{18,37}$ The mean age of our study group was 28 years, and impaired glucose metabolism was already manifest in about a quarter of the women. Of importance, the subgroup of women with abnormal glucose tolerance as well as polycystic ovary syndrome manifested more and greater predisposing risk factors for cardiovascular diseases. In fact, they were significantly more obese and hypertensive, and exhibited a more adverse lipid profile and increased hemoglobin $\mathrm{A}_{1 \mathrm{C}}$ measurements than those whose glucose tolerance was in the normal range. Since the rate of conversion from impaired glucose tolerance to type 2 diabetes is accelerated among women with polycystic ovary syndrome ${ }^{18}$ the early recognition and treatment of impaired glucose tolerance in such patients is impor-

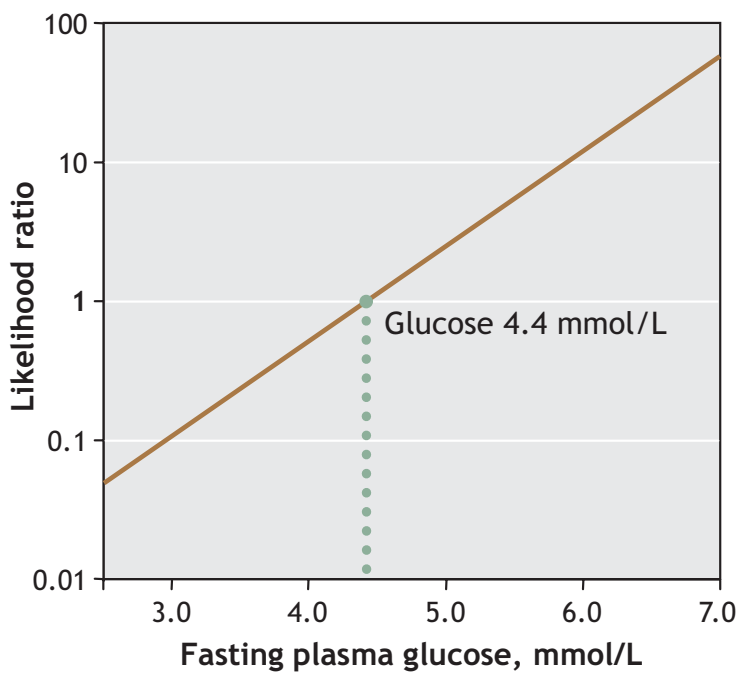

Fig. 3: A logarithmic representation of the likelihood ratio of having abnormal glucose tolerance, as a function of fasting plasma glucose test results. At a glucose concentration of $4.4 \mathrm{mmol} / \mathrm{L}$, the likelihood of finding that test result among patients with abnormal glucose tolerance is equal to its likelihood among those with normal glucose tolerance. 
tant from an individual and societal perspective. Since women with the syndrome usually consult early for clinical manifestations of hyperandrogenemia or anovulation, clinicians have that opportunity for screening and possibly preventing future development of type 2 diabetes or cardiovascular diseases in this population. This is particularly relevant because effective strategies to prevent type 2 diabetes are available. ${ }^{24,25}$

The most important quality of a screening test is to be sufficiently sensitive to avoid missing diagnoses. The minimal sensitivity generally recommended for a screening test is therefore $80 \% .{ }^{33,34}$ If the most conservative cutoff value for the results of fasting plasma glucose tests (i.e., $5.6 \mathrm{mmol} / \mathrm{L}$, as recommended by the American Diabetes Association) were used to screen for abnormal glucose tolerance in our group of women with polycystic ovary syndrome, $52 \%$ of affected women would have been missed, reflecting the low sensitivity of this test: $48 \%$. Even when using a cutoff of $5.0 \mathrm{mmol} / \mathrm{L}$, the threshold associated the highest possible levels of both sensitivity $(76 \%)$ and specificity $(78 \%)$, an unacceptable percentage of glucose-intolerant women remained undiagnosed: $24 \%$. Notably, this limit was similar to the optimal cutoff determined by Palmert and associates ${ }^{26}$ in adolescent girls with polycystic ovary syndrome: $4.8 \mathrm{mmol} / \mathrm{L}$. In that small study of 27 girls, the sensitivity $(78 \%)$ and specificity $(72 \%)$ found were comparable to those in our group; the authors likewise concluded that fasting plasma glucose was not a reliable screening tool for adolescents with polycystic ovary syndrome. ${ }^{26}$

Furthermore, likelihood ratios modelled for specific fasting plasma glucose values (Fig. 3) reveal that values must be very low to progressively rule out abnormal glucose tolerance in women with polycystic ovary syndrome: only glucose values below $4.4 \mathrm{mmol} / \mathrm{L}$ are associated with fasting-plasmaglucose-specific likelihood ratios below I.o.

Finally, we found that the 2 most important independent predictors of abnormal glucose tolerance were fasting plasma glucose and triglyceride levels. Of note, it was not possible to determine if hemoglobin $A_{1 c}$ level is a significant independent predictor of abnormal glucose tolerance because it was measured in only $38 \%$ of our subjects. Combining cutoffs for these factors is easily performed in clinical care settings and may actually be a better screening tool than fasting plasma glucose testing. Indeed, restricting oral glucose tolerance tests to women with polycystic ovary syndrome with test results for both fasting plasma glucose of $4.2 \mathrm{mmol} / \mathrm{L}$ or more and triglycerides of $\mathrm{I} .5 \mathrm{mmol} / \mathrm{L}$ or more would avoid more oral glucose tolerance tests (in our case, $38 \%$ of the women whose results were positive) with a far better specificity ( $78 \%$; data not shown). However, these combined criteria should nonetheless be validated in a large group of women with polycystic ovary syndrome before they can be recommended.

Among our 24 nonobese women (BMI $\left.\leq 30 \mathrm{~kg} / \mathrm{m}^{2}\right)$ with polycystic ovary syndrome, one had a fasting plasma glucose above $5.6 \mathrm{mmol} / \mathrm{L}(4.2 \%)$ and 3 had abnormal glucose tolerance (I2.5\%; data not shown). Interestingly, the one woman with a fasting plasma glucose result above $5.6 \mathrm{mmol} / \mathrm{L}$ was found to have a normal glucose tolerance (specificity $95 \%$ ), and all nonobese women whose tolerance was abnormal had a fasting test result under $5.6 \mathrm{mmol} / \mathrm{L}$ (zero sensitivity; data not shown). However, extrapolation of our conclusions speci- fically to nonobese women with polycystic ovary syndrome should be done with caution, in consideration of the lower statistical power of this subgroup analysis. Although a referral bias may have increased the overall prevalence of abnormal glucose tolerance in our study (impaired tolerance $23 \%$, type 2 diabetes $5 \%$ ), we believe this bias to have been unimportant because the observed prevalence was even lower than those reported in the literature: abnormal glucose tolerance $31 \%-35 \%$, type 2 diabetes $7.5 \%-10 \%{ }^{18,19}$

In conclusion, our results demonstrate that the fasting glucose test is not sufficiently sensitive to be used to screen for abnormal glucose tolerance in women with polycystic ovary syndrome. Moreover, our results directly challenge the fasting plasma glucose cutoffs recommended by the Canadian and American Diabetes Associations to screen people at risk for abnormal glucose tolerance with an oral glucose tolerance test, which are inappropriate for women with polycystic ovary syndrome. Since the oral glucose tolerance test remains the best standardized test to accurately identify abnormal glucose tolerance in this population, we recommend the use of that test to diagnose abnormal glucose tolerance among all women with polycystic ovary syndrome.

\section{This article has been peer reviewed.}

From the Department of Medicine, Division of Endocrinology, Université de Sherbrooke, Sherbrooke, Que.

\section{Competing interests: None declared.}

Contributors: Claudia Gagnon participated in study design, ascertained data quality, reviewed subjects' charts, contributed to the data analyses and drafted the manuscript. Jean-Patrice Baillargeon generated the hypothesis and study objectives, designed the study, extracted test results from the database, analyzed the data and reviewed the manuscript. Both authors approved the final version for publication.

Acknowledgement: Jean-Patrice Baillargeon is a Junior 1 Clinical Investigator of the Fonds de la recherche en santé du Québec (\#3158).

\section{REFERENCES}

I. Asuncion M, Calvo RM, San Millan JL, et al. A prospective study of the prevalence of the polycystic ovary syndrome in unselected Caucasian women from Spain. $J$ Clin Endocrinol Metab 2000;85:2434-8.

2. Diamanti-Kandarakis E, Kouli CR, Bergiele AT, et al. A survey of the polycystic ovary syndrome in the Greek island of Lesbos: hormonal and metabolic profile. $J$ Clin Endocrinol Metab 1999;84:4006-II.

3. Knochenhauer ES, Key TJ, Kahsar-Miller M, et al. Prevalence of the polycystic ovary syndrome in unselected black and white women of the southeastern United States: a prospective study. J Clin Endocrinol Metab 1998;83:3078-82.

4. Toprak S, Yonem A, Cakir B, et al. Insulin resistance in nonobese patients with polycystic ovary syndrome. Horm Res 2001;55:65-70.

5. Ciampelli M, Fulghesu AM, Cucinelli F, et al. Heterogeneity in $\beta$ cell activity, hepatic insulin clearance and peripheral insulin sensitivity in women with polycystic ovary syndrome. Hum Reprod 1997;12:1897-90I.

6. Sinagra D, Scarpitta AM, Brigandi M, et al. Feedback inhibition of insulin secretion and insulin resistance in polycystic ovarian syndrome with and without obesity. Eur Rev Med Pharmacol Sci 1997;I:I67-7I.

7. Dunaif A, Segal KR, Shelley DR, et al. Evidence for distinctive and intrinsic defects in insulin action in polycystic ovary syndrome. Diabetes 1992;4I:1257-66.

8. Chang RJ, Nakamura RM, Judd HL, et al. Insulin resistance in nonobese patients with polycystic ovarian disease. JClin Endocrinol Metab I983;57:356-9.

9. Holte J, Bergh T, Berne C, et al. Enhanced early insulin response to glucose in relation to insulin resistance in women with polycystic ovary syndrome and normal glucose tolerance. J Clin Endocrinol Metab 1994;78:1052-8.

Io. Dunaif A, Segal KR, Futterweit W, et al. Profound peripheral insulin resistance, independent of obesity, in polycystic ovary syndrome. Diabetes I989;38:1165-74.

II. Baillargeon JP. Use of insulin sensitizers in polycystic ovarian syndrome. Curr Opin Investig Drugs 2005; 6:I012-22. 
I2. Baillargeon JP, Nestler JE. Polycystic ovary syndrome: a syndrome of ovarian hypersensitivity to insulin? J Clin Endocrinol Metab 2006;91:22-4.

I3. Veldhuis JD, Zhang G, Garmey JC. Troglitazone, an insulin-sensitizing thiazolidinedione, represses combined stimulation by $\mathrm{LH}$ and insulin of de novo androgen biosynthesis by thecal cells in vitro. JClin Endocrinol Metab 2002;87:1129-33.

I4. Sekar N, Lavoie HA, Veldhuis JD. Concerted regulation of steroidogenic acute regulatory gene expression by luteinizing hormone and insulin (or insulin-like growth factor I) in primary cultures of porcine granulosa-luteal cells. Endocrinology 2000; I4I:3983-92.

I5. Zhang G, Garmey JC, Veldhuis JD. Interactive stimulation by luteinizing hormone and insulin of the steroidogenic acute regulatory (StAR) protein and $17 \alpha$-hydroxylase/ 17 , 20-lyase (CYPI7) genes in porcine theca cells. Endocrinology 2000;I4I:2735-42.

16. Barbieri RL. Insulin stimulates androgen accumulation in incubations of minced porcine theca. Gynecol Obstet Invest 1994:37:265-9.

17. Nestler JE, Powers LP, Matt DW, et al. A direct effect of hyperinsulinemia on serum sex hormone-binding globulin levels in obese women with the polycystic ovary syndrome. JClin Endocrinol Metab ig91;72:83-9.

I8. Ehrmann DA, Barnes RB, Rosenfield RL, et al. Prevalence of impaired glucose tolerance and diabetes in women with polycystic ovary syndrome. Diabetes Care I999;22:I4I-6.

I9. Legro RS, Kunselman AR, Dodson WC, et al. Prevalence and predictors of risk for type 2 diabetes mellitus and impaired glucose tolerance in polycystic ovary syndrome: a prospective, controlled study in 254 affected women. J Clin Endocrinol Metab I999;84:I65-9.

20. Ehrmann DA, Liljenquist DR, Kasza K, et al. Prevalence and predictors of the metabolic syndrome in women with polycystic ovary syndrome. J Clin Endocrinol Metab 2006;91:48-53.

2I. Lo JC, Feigenbaum SL, Yang J, et al. Epidemiology and adverse cardiovascular risk profile of diagnosed polycystic ovary syndrome. J Clin Endocrinol Metab 2006;91:1357-63.

22. Solomon CG, Hu FB, Dunaif A, et al. Menstrual cycle irregularity and risk for future cardiovascular disease. JClin Endocrinol Metab 2002;87:2013-7.

23. Cibula D, Cifkova R, Fanta M, et al. Increased risk of non-insulin dependent diabete mellitus, arterial hypertension and coronary artery disease in perimenopausa women with a history of the polycystic ovary syndrome. Hum Reprod 2000;15:785-9.

24. Tuomilehto J, Lindstrom J, Eriksson JG, et al. Prevention of type 2 diabetes mellitus by changes in lifestyle among subjects with impaired glucose tolerance. $N$ Eng JMed 200I;344:1343-50.

25. Knowler WC, Barrett-Connor E, Fowler SE, et al. Reduction in the incidence of type 2 diabetes with lifestyle intervention or metformin. N Engl J Med 2002;346:393-403.
26. Palmert MR, Gordon CM, Kartashov AI, et al. Screening for abnormal glucose tolerance in adolescents with polycystic ovary syndrome. J Clin Endocrinol Metab 2002;87:1017-23.

27. Ur E, Capes S, Hanna A, et al. Canadian Diabetes Association Clinical Practice Guidelines Expert Committee. 2003 clinical practice guidelines on the prevention and management of diabetes in Canada: Screening and prevention. Can J Diabetes 2003;27(Suppl 2):Sio-3.

28. American Diabetes Association. Standards of medical care in diabetes - 2006. Diabetes Care 2006;29(Suppl I):S4-42.

29. Zawadsky JK, Dunaif A. Diagnostic criteria for polycystic ovary syndrome: towards a rational approach. In: Dunaif A, Givens JR, Haseltine FP, et al., editors. Current issues in endocrinology and metabolism: polycystic ovary syndrome. Cambridge: Blackwell Scientific Publications; 1992. p. 377-384.

30. Rotterdam ESHRE/ASRM-Sponsored PCOS Consensus Workshop Group. Revised 2003 consensus on diagnostic criteria and long-term health risks related to polycystic ovary syndrome. Fertil Steril 2004;81:19-25.

3I. Sodergard R, Backstrom T, Shanbhag V, et al. Calculation of free and bound fractions of testosterone and estradiol-17 $\beta$ to human plasma proteins at body temperature. J Steroid Biochem I982;16:80I-Io.

32. Friedewald WT, Levy RI, Fredrickson DS. Estimation of the concentration of lowdensity lipoprotein cholesterol in plasma, without use of the preparative ultracentrifuge. Clin Chem I972;18:499-502.

33. Sackett DL, Haynes RB, Guyatt GH, et al. Clinical epidemiology: how to do clinical practice research. rd ed. Philadelphia: Lippincott Williams and Wilkins; 2005.

34. Greenhalgh T. How to read a paper. Papers that report diagnostic or screening tests. $B M J$ I997;315:540-3.

35. Sackett DL, Haynes RB, Guyatt GH, et al. Clinical epidemiology: a basic science for clinical medicine. 2nd ed. Philadelphia: Lippincott Williams and Wilkins; I99I.

36. Albert A. On the use and computation of likelihood ratios in clinical chemistry. Clin Chem I982;28:1113-9.

37. Lo JC, Feigenbaum SL, Yang J, et al. Epidemiology and adverse cardiovascular risk profile of diagnosed polycystic ovary syndrome. JClin Endocrinol Metab 2006;9I:1357-63.

Correspondence to: Dr. Jean-Patrice Baillargeon, Université de Sherbrooke, Sherbrooke QC $\mathrm{J1H}_{5} \mathrm{~N}_{4}$; fax 819 564-5292; jp.baillargeon@usherbrooke.ca 